\title{
Development of Relative Clause Constructions in English L2
}

\author{
Yumiko Yamaguchi (Corresponding author) \\ Foreign Language Center, Tokai University, 4-1-1 Kitakaname, Hiratsuka-City, Kanagawa 259-1292 Japan \\ E-mail: yyamaguchi@tokai-u.jp \\ Satomi Kawaguchi \\ School of Humanities \& Communication Arts, University of Western Sydney, Locked Bag 1797, Penrith, NSW 2751, Australia \\ E-mail: s.kawaguchi@uws.edu.au
}

Received: 29-05-2015

Published: 01-01-2016
Accepted: 14-09-2015

doi:10.7575/aiac.ijalel.v.5n.1p.83
Advance Access Published: October 2015

URL: http://dx.doi.org/10.7575/aiac.ijalel.v.5n.1p.83

\begin{abstract}
This study explores how relative clause (RC) constructions develop in the acquisition of English as a second language (L2). The acquisition of RC constructions has been the focus of much research in the field of language acquisition, but a majority of L2 studies in this area is experimental based on the Noun Phrase Accessibility Hierarchy (NPAH) (Keenan \& Comrie, 1977). In this study, the spontaneous speech production by a Japanese primary school child, learning English in a naturalistic environment, was audio-recorded regularly over two years, and the development of RC constructions was compared with the acquisition of other English morphological and syntactic structures as represented within Processability Theory (PT) (Pienemann, 1998; Pienemann, Di Biase, \& Kawaguchi, 2005; Pienemann \& Keßler, 2011). Although PT predicts that subordinate clauses are acquired at the highest stage in processability hierarchy, the results in this longitudinal study show that some types of RC constructions emerge at earlier stages in L2 English acquisition. The results also show that RC constructions in the Japanese child's English L2 develop in the similar way to those reported in L1 studies (e.g., Diessel, 2004).
\end{abstract}

Keywords: relative clause constructions, English L2, Processability Theory, the Noun Phrase Accessibility Hierarchy, Japanese child

\section{Introduction}

A relative clause (RC) is "a clause modifying the head noun within a noun phrase" (Kroeger, 2005, p.230). The development of RCs has been the focus of much language acquisition research in both first language (L1) (e.g., Diessel, 2004; Diessel \& Tomasello, 2001, 2005; Kidd \& Bavin, 2002; Sheldon, 1974) and second language (L2) contexts (e.g., Doughty, 1991: Eckman, Bell, \& Nelson, 1988; Gass, 1979; Izumi, 2003; Pavesi, 1986). However, most of the previous studies are experimental and few longitudinal studies on this issue have been conducted. In particular, while the use of RCs in children's spontaneous speech in L1 acquisition has been examined to some extent (e.g., Bowerman, 1979; Bloom, 1991; Diessel, 2004), longitudinal studies on L2 learners (e.g., Mellow, 2006; Schumann, 1980) are very rare. Moreover, a majority of previous studies focused on the acquisition of RCs in terms of Noun Phrase Accessibility Hierarchy (NPAH) (Keenan \& Comrie, 1977). Thus, this study investigates the developmental stages for various RC constructions in details with longitudinal data using one of the current major approaches in the field of second language acquisition (SLA), namely Processability Theory (Pienemann, 1998; Pienemann, Di Biase, \& Kawaguchi, 2005; Pienemann \& Keßler, 2011).

\section{Background}

\subsection{Noun Phrase Accessibility Hierarchy}

Based on a typological investigation of more than 50 different languages, Keenan \& Comrie (1977) proposed the Noun Phrase Accessibility Hierarchy (NPAH) and suggest that there is a particular markedness order to the different relative clause types that applies to all languages in the world. According to the NPAH, there are six types of relativization in English, and each is distinguished by the grammatical function of the head noun inside the RC as shown in Table 1. According to Keenan and Comrie, the NPAH is described as: $\mathrm{SU}>\mathrm{DO}>\mathrm{IO}>\mathrm{OBL}>\mathrm{GEN}>\mathrm{OCOMP}$.

Table 1. English Relativization Types (After Ellis, 1994, p.102)

\begin{tabular}{ll}
\hline Type & Example \\
\hline Subject (SU) & The man who lives next door ... \\
\hline Direct object (DO) & The man whom I saw ... \\
\hline Indirect object (IO) & The man to whom I gave a present ... \\
\hline Oblique (OBL) & The man about whom we spoke ... \\
\hline Genitive (GEN) & The man whose wife had an accident ... \\
\hline Object of comparative (OCOMP) & The man that I am richer than ... \\
\hline
\end{tabular}


In the NPAH, positions at the left end of the scale are easier to relativize than positions on the right. If a language can form RC on a given position on the hierarchy, it can also form RCs on all positions higher (to the left) on the hierarchy. For instance, a language that can relativize on indirect objects will also be able to relativize on subject and object NPs, but possibly not on genitive NPs. The relativization types located to the left are considered to be less marked, and those to the right are regarded as more marked. The NPAH has been used to explain in the general empirical finding that subject RCs have been shown to be easier to process in comparison to object RCs. However, the NPAH is concerned only with the functions of relative pronouns within the RCs. That is, it does not deal with the functions of relativized noun phrases in the matrix clauses.

\subsection{Processability Theory}

This study uses Processability Theory (PT) (Pienemann, 1998; Pienemann, Di Biase \& Kawaguchi, 2005; Pienemann \& Keßler, 2011) as a theoretical framework for analyzing the learner's development of RC constructions. PT predicts a universal hierarchy of processing procedures, which are required for producing linguistic structures, based on Levelt's (1989) speech production model and Lexical Functional Grammar (LFG) (e.g., Bresnan, 2001; Dalrymple, 2001). According to PT, learners, at any stage of development, are able to produce only those linguistic structures which the current stage of their language processors can handle. PT assumes that the processing procedures develop in the following sequence: the lemma $>$ the category procedure $>$ phrasal procedure $>$ inter-phrasal procedure $>$ inter-clausal procedure.

In PT, subordinate clauses are placed at the inter-clausal procedure (i.e., S-procedure) stage since matrix and embedded clauses are processed separately. RC constructions involve information processing across clauses as one of the arguments in the RC needs to link to a referent within the main clause. Hence, the Topic Hypothesis and the Lexical Mapping Hypothesis in PT (Pienemann, Di Biase \& Kawaguchi, 2005) may offer a possible framework to account for the acquisition of RCs. Table 2 and Table 3 show the developmental stages of English syntactic structures based on the Topic and the Lexical Mapping Hypothesis respectively. In the following, RC constructions are interpreted in terms of PT stages. LFG is used to represent the grammatical structure formally.

Table 2. Developmental Stages for English Syntax Based on the Topic Hypothesis (after Pienemann, Di Biase \& Kawaguchi, 2005)

\begin{tabular}{|c|c|c|}
\hline STAGE & STRUCTURE & EXAMPLE \\
\hline $\mathrm{XP}_{\text {TOP }}$ MARKED ALIGNMENT & OBJ topicalisation & ice cream she likes \\
\hline $\mathrm{XP}_{\text {TOP UNMARKED ALIGNMENT }}$ & $\mathrm{TOP}_{\mathrm{ADJ}}$ canonical order & $\begin{array}{l}\text { tomorrow they go home } \\
\text { in Australia people eat pies }\end{array}$ \\
\hline UNMARKED ALIGNMENT & canonical word order & $\begin{array}{l}\text { Mary jumped } \\
\text { he working } \\
\text { John eat rice }\end{array}$ \\
\hline LEMMA ACCESS & $\begin{array}{l}\text { single words } \\
\text { formulas }\end{array}$ & $\begin{array}{l}\text { station, here } \\
\text { my name is Pim }\end{array}$ \\
\hline
\end{tabular}

Table 3. Developmental stages for English syntax based on the Lexical Mapping Hypothesis (after Pienemann, et al, 2005)

\begin{tabular}{|c|c|c|}
\hline STAGE & CONSTRUCTIONS & EXAMPLES \\
\hline $\begin{array}{l}\text { NON-DEFAULT } \\
\text { MAPPING }\end{array}$ & $\begin{array}{l}\text { passives, causatives, benefactives, } \\
\text { exceptional verb constructions, etc. }\end{array}$ & $\begin{array}{l}\text { the red fish was eaten by the green fish } \\
\text { Joan made her daughter study hard }\end{array}$ \\
\hline $\begin{array}{l}\text { DEFAULT MAPPING } \\
\text { AND ADDITIONAL } \\
\text { ARGUMENTS }\end{array}$ & $\begin{array}{l}\text { agent/experiencer, patient/theme, and/or } \\
\text { other members of the a-structure hierarchy, } \\
\text { such as goals and locatives }\end{array}$ & $\begin{array}{l}\text { Mary put the sugar in cupboard } \\
\text { Mary gave John a new bicycle } \\
\text { John went to Florence in train }\end{array}$ \\
\hline DEFAULT MAPPING & agent/experiencer and/or patient/theme & $\begin{array}{l}\text { my brother sleeping } \\
\text { John fry egg }\end{array}$ \\
\hline
\end{tabular}

According to Kroeger (2005), the noun phrase (NP) which contains an RC is called a "RC construction", while RC refers only to the clausal modifier. In LFG, RCs in English and many other languages are considered to involve longdistance dependencies. According to Darlymple (2001), two long-distance dependencies are involved in an RC construction. The first dependency holds between the fronted phrase and the within-clause grammatical function it fills. Bresnan \& Mchombo (1987) claim that a fronted relative pronoun in an RC bears syntacticized TOPIC (TOP) function. The TOP function must be linked to a grammatical function within the clause. The second dependency involves the relative pronoun and its position, possibly embedded, within the fronted phrase. The Figure 1 shows the constituentstructure and functional-structure for the phase "a man who Chris saw". It is indicated that the relative pronoun appears in initial position in the $\mathrm{RC}$, and its $\mathrm{f}$ (unctional)-structure is both the TOP and the relative pronoun (REL PRO) of the $\mathrm{RC}$. 


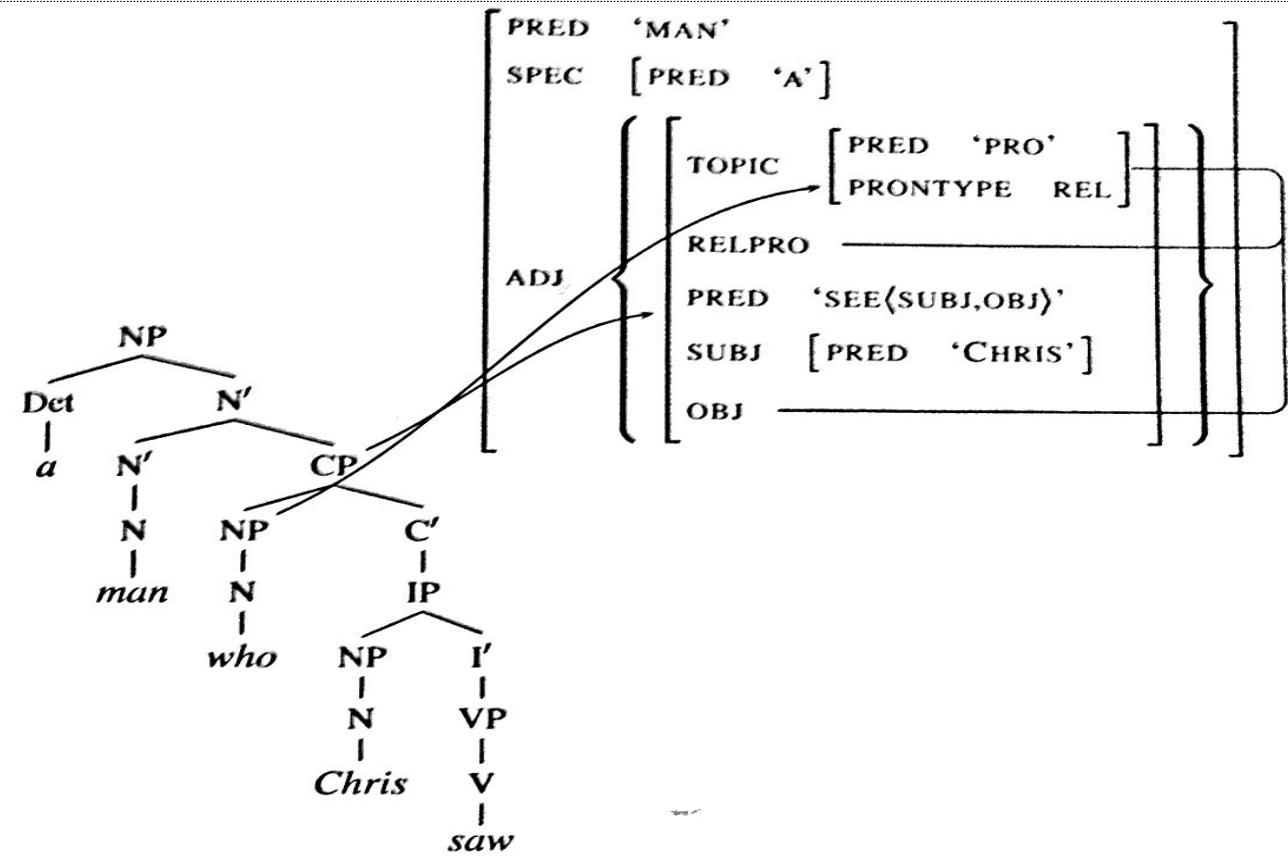

Figure 1. Two long-distance dependencies involved in RC construction (After Dalrymple, 2001, p.401)

Since all of RCs create marked alignment due to long-distance dependencies, PT predicts that RCs are acquired after the "XP + Unmarked Alignment" stage (see Table 2). Further, RC constructions (i.e., not only the RC itself but both matrix clause and RC) are predicted to be acquired after the S-procedure stage when they involve long distance dependencies in the subordinate clause. However, this means that, piling all of those RCs within one single stage, PT has little to predict by comparison, for instance, to Keenan and Comrie's NPAH (SUBJ > DO etc.). Minimally, PT would have to look at sequences within that high stage and make some sense of their order.

Since different RC constructions involve different degrees of non-canonicity, it can be assumed that all RC constructions involve non-canonical alignment. However, additional non-canonicity can happen with centre-embedded RC constructions and non-default mapping. Centre-embedded RC constructions are involved in additional noncanonicity in c(onstituent)-structure as shown in (1). Perceptual Difficulty Hypothesis (PDH) (Kuno, 1974) also states that centre-embedded RCs are perceptually more difficult to process than sentence-final RC constructions are as shown in (2).

(1) The boy [who sees the police man] chases the girl.

(2) The chases the girl [who sees the policeman]. (MacWhinney \& Pleh, 1988)

According to the Lexical Mapping Hypothesis in PT, RCs containing two propositions, as in (3), due to the thematic fusion, are acquired later than those with a single proposition, as in (4). The thematic role of "the girl" in (3) can be the patient of the verb "chase" as well as the experiencer of the verb "see".

(3) The boy chases the girl [who sees the policeman].

(4) This is the girl [who sees the policeman].

Table 4 summarizes non-canonicity in RC constructions based on the Topic Hypothesis and the Lexical Mapping Hypothesis. In the table, the arrows indicate the increased degree of non-canonicity.

Table 4. Non-Canonicity in RC Constructions

\begin{tabular}{|l|l|}
\hline $\begin{array}{l}\text { Non-canonical alignment } \\
\text { Topic Hypothesis (c-f mapping) }\end{array}$ & $\begin{array}{l}\text { Non-canonical alignment } \\
\text { Topic Hypothesis (c-f mapping) } \\
\text { PLUS }\end{array}$ \\
\hline $\begin{array}{l}\text { Non-default mapping } \\
\text { Lexical Mapping Hypothesis (a-f mapping) }\end{array}$ \\
\hline $\begin{array}{l}\text { This is the frog [which I saw] } \\
\text { (additional non-canonicity) } \\
\text { tiny. }{ }^{\text {I) }}\end{array}$ & $\begin{array}{l}\text { (additional non-canonicity) } \\
\text { This is the frog [which was kicked by Tom]. }{ }^{2)} \\
\text { Ifed the frog [which I found]. }{ }^{3)}\end{array}$ \\
\hline
\end{tabular}


1) Centre-embedded RCs create additional non-canonicity in c-structure

2) Passive in $R C$

3) The head noun receives two thematic roles (i.e., thematic fusion)

4) Passive in RC plus thematic fusion

5) Centre-embedded RC plus passive in RC plus thematic fusion

\subsection{Previous Studies}

The development of English RCs in first language (L1) acquisition has been conducted extensively in both experimental (e.g., Clark, 2003; Diessel \& Tomasello, 2005; Kidd \& Bavin, 2002; Sheldon, 1974) and longitudinal (e.g., Bowerman, 1979; Bloom, 1991; Diessel, 2004; Diessel \& Tomasello, 2000, 2001, 2005; Limber, 1973) studies. These L1 studies indicate children start from RC constructions containing a single proposition, that is, presentational constructions describing a single situation, and then children gradually learn the use of complex RC constructions containing two propositions.

According to L1 studies on RCs (e.g., Diessel, 2004; Diessel and Tomasello, 2000), children use presentational amalgam constructions, as in "that's doggy turn around", several months before presentational RC constructions emerged in their speech. This construction contains a presentational copular clause and a verb phrase that one might analyze as a RC in which the relative pronoun or complementizer is absent (Lambrecht, 1988). Presentational amalgam constructions are regarded as precursors to the presentational RC constructions. L1 studies (e.g., Diessel 2004; Diessel \& Tomasello, 2000, 2001, 2005) also show that center-embedded RCs rarely appeared in children's spontaneous speech.

The majority of L2 studies on the acquisition of English RCs have been conducted cross-sectionally (e.g., Doughty, 1991; Eckman, Bell \& Nelson, 1988; Gass, 1979; Izumi, 2003; Pavesi, 1986). As for longitudinal studies, Schumann (1980) examined the acquisition order of RCs in the speech production of 5 Spanish L1 learners for 10 months. More recently, Mellow (2006) observed written narratives by a 12-year-old Spanish L1 learner for 7 months using fifteen different wordless picture books. These studies found that center-embedded RCs were rarely used by L2 learners as found in L1 studies. However, more research with longitudinal data is needed to investigate whether RC constructions develop in the same manner in both L1 and L2 acquisition.

English morphology and syntax predicted in PT have been tested with longitudinal data to some extent (e.g., Di Biase, Kawaguchi, \& Yamaguchi, 2015; Kawaguchi \& Yamaguchi, 2014; Itani-Adams, 2007; Yamaguchi, 2013a, 2013b ) and the acquisition of L2 complex structures has attracted attention of some recent PT research (Baten \& Håkansson, 2015; Yamaguchi, 2013b). However, the issues of how various RC constructions develop in L2 acquisition have not yet been addressed extensively (Yamaguchi \& Kawaguchi, 2013).

\section{Study}

\subsection{Research Questions and Hypotheses}

In order to fill the gaps in L2 acquisition research and PT studies, four research questions are formulated as follows:

1. When do RC constructions emerge in relation to PT general developmental stages of English L2 morphology and syntax?

2. Does the acquisition of RC constructions in the acquisition of English L2 by a Japanese child follow the Noun Phrase Accessibility Hierarchy (NPAH)?

3. Do RC constructions containing single proposition emerge in L2 before RC constructions containing two propositions in the child English L2 acquisition, just like L1 acquisition?

4. Are centre-embedded RC constructions acquired after sentence final-embedded RC constructions by the Japanese child, as found in L1 acquisition studies?

For the first research question, since RC constructions exhibit marked alignment, we hypothesize that RC constructions emerge after the learner acquires inter-phrasal procedure (i.e., S-procedure) in morphology and marked alignment in syntax.

According to the NPAH, the processing load increases with the distance between filler and gap: SUBJ > OBJ > ID OBJ $>$ OBL > Possessor (GEN) > OCOMP. Thus, we hypothesize that Possessor (GEN) and OCOMP are acquired late due to the high degree of embeddedness. However, we are not sure about the order of acquisition for SUBJ, OBJ, ID OBJ, and OBL.

While the head noun which RC modifies bears one argument role with RC constructions with a single proposition, it receives two arguments roles in those with the two propositions. Hence, we hypothesize that RC constructions with two propositions require more processing load due to their non-default mapping, thus they are acquired later than RC constructions with single proposition based on PT's Lexical Mapping Hypothesis.

Furthermore, we hypothesize that center-embedded RC constructions are acquired after sentence final-embedded RC constructions since the former involves additional non-canonicity in c-structure as well as long-distance dependencies. 


\subsection{The Informant}

This study examined a Japanese female child, Kumi (code name), learning English in a naturalistic environment in Australia. Although she was raised as Japanese monolingual until she was 5 years 7 months, she participated in an English activity program instructed by a native speaker of English for 2 hours per week for 32 weeks in Japan, that is, the age from 4 years 10 months to 5 years 6 months. However, when she moved to Australia with her family and started attending local primary school at the age of 5 years 7 months, her English was limited to basic words and formulaic expressions (e.g., thank you, I don't know).

\subsection{Data Collection}

The child's spontaneous speech in English was audio-recorded regularly, as shown in Table 5, when she was 5 years 8 months to 7 years 8 months. That is, the data collection started 4 weeks after her exposure to English started in Australia.

Table 5. Kumi’s Exposure to English in Australia

\begin{tabular}{lcccccccccccccc}
\hline time & $\mathbf{t 1}$ & $\mathbf{t 2}$ & $\mathbf{t 3}$ & $\mathbf{t 4}$ & $\mathbf{t 5}$ & $\mathbf{t 6}$ & $\mathbf{t 7}$ & $\mathbf{t 8}$ & $\mathbf{t 9}$ & $\mathbf{t 1 0}$ & $\mathbf{t 1 1}$ & $\mathbf{t 1 2}$ & $\mathbf{t 1 3}$ & $\mathbf{t 1 4}$ \\
\hline $\begin{array}{l}\text { Exposure to English } \\
\text { in Australia (weeks) }\end{array}$ & 4 & 6 & 8 & 10 & 12 & 20 & 28 & 36 & 44 & 52 & 64 & 76 & 88 & 100 \\
\hline
\end{tabular}

In order to elicit the child speech production in English, several tasks, such as semi-structure interview, narratives, and communication games, were utilized. Each session lasted for 20 to 40 minutes according to the child's motivation. All the audio-recorded sessions were transcribed.

\subsection{Data size}

The data size of each interview was calculated using computer software (i.e., KWIC) and summarized in Table 6. In the table, the first column presents the time of the data collection session, the second column her age, and the third column the total number of turns. Kumi's ages are indicated in the format 'year: month, day'. The fourth and fifth columns shows the number of words (i.e., tokens) and the number of different words (i.e., types) produced by the child. The last column shows the type/token ratio at each data collection session.

Table 6. Data Size in Kumi’s Longitudinal Study

\begin{tabular}{|c|c|c|c|c|c|}
\hline Time & Kumi's age & $\begin{array}{l}\text { Total number } \\
\text { of turns }\end{array}$ & $\begin{array}{c}\text { Total number of words } \\
\text { (tokens) }\end{array}$ & $\begin{array}{c}\text { Total number of different words } \\
\text { (types) }\end{array}$ & Type/Token ratio \\
\hline $\mathrm{t} 1$ & $5 ; 8,15$ & 25 & 176 & 52 & 0.30 \\
\hline $\mathrm{t} 2$ & $5 ; 9,0$ & 322 & 1307 & 321 & 0.25 \\
\hline $\mathrm{t} 3$ & $5 ; 9,15$ & 123 & 289 & 112 & 0.39 \\
\hline $\mathrm{t} 4$ & $5 ; 10,0$ & 191 & 682 & 221 & 0.32 \\
\hline t5 & $5 ; 10,14$ & 129 & 500 & 167 & 0.33 \\
\hline t6 & $6 ; 0,15$ & 190 & 957 & 268 & 0.28 \\
\hline $\mathrm{t} 7$ & $6 ; 2,13$ & 153 & 654 & 221 & 0.34 \\
\hline t8 & $6 ; 4,15$ & 100 & 482 & 177 & 0.37 \\
\hline t9 & $6 ; 6,15$ & 156 & 1108 & 322 & 0.29 \\
\hline $\mathrm{t} 10$ & $6 ; 8,13$ & 124 & 1060 & 345 & 0.33 \\
\hline $\mathrm{t} 11$ & $6 ; 11,15$ & 112 & 957 & 300 & 0.31 \\
\hline $\mathrm{t} 12$ & $7 ; 2,12$ & 122 & 793 & 256 & 0.32 \\
\hline $\mathrm{t} 13$ & $7 ; 5,13$ & 214 & 1203 & 359 & 0.30 \\
\hline $\mathrm{t} 14$ & $7 ; 8,15$ & 190 & 1783 & 504 & 0.28 \\
\hline Total & & 2151 & 11951 & 3625 & 0.31 \\
\hline
\end{tabular}

It should be noted that conversations fillers (e.g., um, er), fragments of words, and other non-words have been excluded when counting the token and types of words.

\subsection{Data Analysis}

In order to compare the development of RC constructions with the acquisition of other English morphological and syntactic structures, the distributional analyses of speech data were conducted for linguistic structures listed in PT stages and RC constructions. English morphological and syntactic structures examined in this study based on PT are summarized in Table 7 and Table 8 respectively. 
Table 7. English morphological structures predicted in PT stages (after Pienemann, 1998, 2005)

\begin{tabular}{|c|c|c|c|}
\hline STAGE / PROCEDURE & $\begin{array}{l}\text { MORPHOLOGICAL } \\
\text { OUTCOME }\end{array}$ & STRUCTURE & EXAMPLE \\
\hline 4. S-PROCEDURE & $\begin{array}{l}\text { INTER-PHRASAL } \\
\text { MORPHOLOGY }\end{array}$ & 3rd person singular $-S$ & Peter loves rice \\
\hline \multirow[t]{2}{*}{ 3. PHRASAL PROCEDURE } & VP MORPHOLOGY & $\begin{array}{l}\mathrm{AUX}+\mathrm{V}: \\
\text { have + V-ed } \\
\mathrm{MOD}+\mathrm{V} \\
\text { be }+\mathrm{V}-i n g \\
\end{array}$ & $\begin{array}{l}\text { they have walked } \\
\text { you can go } \\
\text { I am going }\end{array}$ \\
\hline & NP MORPHOLOGY & $\begin{array}{l}\text { phrasal plural } \\
\text { marking (with } \\
\text { agreement) }\end{array}$ & $\begin{array}{l}\text { these girls } \\
\text { many dogs } \\
\text { three black cats }\end{array}$ \\
\hline 2. CATEGORY PROCEDURE & LEXICAL MORPHOLOGY & $\begin{array}{l}\text { past }-e d \\
\text { verb -ing } \\
\text { plural }-s \text { (without } \\
\text { agreement) }\end{array}$ & $\begin{array}{l}\text { Mary jumped } \\
\text { he working } \\
\text { I miss my friends }\end{array}$ \\
\hline 1. LEMMA ACCESS & INVARIANT FORMS & Invariant forms & $\begin{array}{l}\text { station, here } \\
\text { my name is Pim }\end{array}$ \\
\hline
\end{tabular}

Table 8. Syntactic structures predicted in PT stages (after Pienemann, 2005)

\begin{tabular}{llll}
\multicolumn{1}{c}{ STAGE } & DECLARATIVES & Y/N QUESTIONS & CONSTITUENT QUESTIONS \\
\hline $\begin{array}{l}\text { 5. XP + MARKED } \\
\text { ALIGNMENT }\end{array}$ & & & $\begin{array}{l}\text { wh- + AUX + SUBJ V (O) }) \\
\text { wh- + Copula + SUBJ X? }\end{array}$ \\
\hline $\begin{array}{l}\text { 4. MARKED } \\
\text { ALIGNMENT }\end{array}$ & OBJ topicalisation & $\begin{array}{l}\text { AUX + SUBJ V }(\mathrm{O}) \text { ? } \\
\text { Copula + SUBJ X? }\end{array}$ & \\
\hline $\begin{array}{l}\text { 3. XP + UNMARKED } \\
\text { ALIGNMENT }\end{array}$ & ADJ + canonical order & AUX do + canonical order? & wh- + canonical order? \\
\hline $\begin{array}{l}\text { 2. UNMARKED } \\
\text { ALIGNMENT }\end{array}$ & canonical order & canonical order? & \\
\hline 1. LEMMA ACCESS & $\begin{array}{l}\text { single constituent } \\
\text { formula }\end{array}$ & single constituent? formula? & $\begin{array}{l}\text { single constituent? } \\
\text { formula? }\end{array}$ \\
\hline
\end{tabular}

RC constructions were coded either as those with two propositions or as those with a single proposition based on Diessel (2004). In order to investigate the developmental path from RCs with single preposition to those with two prepositions, various types of $\mathrm{RC}$ constructions, including presentational (e.g., this is something that I eat), infinitival (e.g., we like fish to eat), and participial (e.g., I have dog eating the doughnut) RCs were also coded following longitudinal studies on children's L1 acquisition (e.g., Diessel, 2004; Diessel \& Tomasello, 2000, 2001, 2005).

Based on PT, this study uses the emergence criterion in order to determine the acquisition point of each grammatical structure. PT claims that the accuracy-based analysis cannot describe the dynamics of linguistic development since even $100 \%$ rule application in a certain session does not guarantee a steady development in the subsequent sessions. Hence, the child is considered to have acquired a grammatical structure when she started using it systematically in this study. As for morphology, it is examined whether the rule is applied more than once in lexically and formally varied contexts following Di Biase and Kawaguchi (2002).

\section{Results}

The results of the distributional analysis for Kumi's morphological development are presented in Table 9. The first row indicates the different point in time $(\mathrm{t} 1, \mathrm{t} 2 \ldots)$ in the corpus. The number in brackets shows that her exposure to English in Australia in weeks. The first stage (i.e., Lemma Access), where invariant forms are assumed to appear, is not included in the table since the child consistently produced those forms from the first session. According to the results shown in this table, Kumi's morphological development is compatible with the developmental stages predicted in PT.

Also, it is found that she attained S-procedure (i.e., inter-phrasal procedure) at Time 9, that is, after 44 weeks exposure to English in Australia.

As for syntactic development, this study focuses on the acquisition of interrogatives since more various structures at higher stages (after XP + Unmarked Alignment stage) were found to emerge in interrogatives than in declaratives in the child speech production. Table 10 and Table 11 present the distribution of Yes/No questions and constituent questions respectively. The numbers at Time 3, 4, 5, and 7 in Table 11 are entered with brackets since those instances can be considered as insufficient evidence for the application of the syntactic rule (i.e., Wh- Copula SUBJ X?). In those instances, the child produced the same question (where are you?) repeatedly and it is possible that she used it as a formulaic expression. The results of the analyses show that Unmarked Alignment emerged at Time 2 and then Marked Alignment at Time 6 for Yes/No questions and Time 8 for constituent questions. This suggests that interrogatives in the child English L2 acquisition developed in the sequence predicted in PT (i.e., Lemma Access > Unmarked Alignment > 
Marked Alignment). However, the child in this study did not produce constituent questions in Unmarked Alignment (i.e., In-Situ Wh- Canonical order?).

Table 12 presents the distribution of RC constructions found in Kumi's speech production. It is found that she produced $65 \mathrm{RC}$ constructions, including infinitival and participial RCs, in total. As for RCs with single proposition, it is found that infinitival RCs emerge at Time 3, presentational RCs at Time 4, presentational RCs and Headless RCs at Time 8, and finally RCs with relative pronouns at Time 9. This suggests that different types of RC constructions developed in the sequence as follows: Infinitival > Participial > Presentational / Headless RCs > RCs with relative pronouns. Regarding RCs with two propositions, they emerged at Time 10 after all types of RC constructions with a single proposition appeared. Thus, it can be considered that RC constructions with two prepositions are acquired those with a single proposition.

Table 9. Kumi’s morphological development (re-analysis of Yamaguchi 2013)

\begin{tabular}{|c|c|c|c|c|c|c|c|c|c|c|c|c|c|c|c|}
\hline STAGE & STRUCTURE & $\begin{array}{l}\mathrm{tl} \\
(4)\end{array}$ & $\begin{array}{l}\mathrm{t} 2 \\
(6)\end{array}$ & $\begin{array}{l}\mathrm{t} \\
(8)\end{array}$ & $\begin{array}{c}\mathrm{t} 4 \\
(10)\end{array}$ & $\begin{array}{l}\text { t5 } \\
(12)\end{array}$ & $\begin{array}{l}\text { t6 } \\
(20)\end{array}$ & $\begin{array}{c}t^{7} \\
(28)\end{array}$ & $\begin{array}{c}t 8 \\
(36)\end{array}$ & $\begin{array}{c}\text { t9 } \\
(44)\end{array}$ & $\begin{array}{l}\mathrm{t} 10 \\
(52)\end{array}$ & $\begin{array}{l}\text { tll } \\
(64)\end{array}$ & $\begin{array}{l}\mathrm{t} 12 \\
(76)\end{array}$ & $\begin{array}{l}\mathrm{t} 13 \\
(88)\end{array}$ & $\begin{array}{c}\mathrm{t} 14 \\
(100)\end{array}$ \\
\hline S-PROCEDURE & $3^{\text {til }}$ pers $5 g-5$ & $>2$ & -2 & f & -1 & -1 & $+1-1$ & $+1-1$ & -2 & $+8-1>1$ & +3 & $2-1$ & +2 & $+4-1$ & $+35-7$ \\
\hline NP PROCEDURE & quantifier $+\mathrm{pl}-s$ & f & -4 & -5 & $f$ & $+1-1$ & l & $+2-2$ & $+1-2$ & $+4-5$ & $+10-8$ & $+4-1$ & $+7-1$ & $+6-3$ & +13 \\
\hline \multirow{2}{*}{ VPPROCEDURE } & $\begin{array}{l}\text { can't/can'will/co } \\
\text { ulan't } \mathrm{V}\end{array}$ & & $+1-1$ & $+1-1$ & +2 & f & / & $+1-1$ & $f$ & +4 & +7 & +7 & +6 & +4 & +13 \\
\hline & $b e$ V-ing & -2 & $+1-1$ & $+1-1$ & $+2-4$ & $+8-2$ & +5 & +11 & +10 & +7 & +5 & +4 & +6 & +6 & +7 \\
\hline \multirow{6}{*}{$\begin{array}{l}\text { CATEGORY } \\
\text { PROCEDURE }\end{array}$} & past $-e d$ & s & $+1-7$ & -2 & -5 & -3 & -2 & $+1-3$ & -2 & $+5-4>3$ & $+4-1>1$ & $+20>2$ & $+5-2$ & $+19-1>1$ & +21 \\
\hline & plural $-s$ & -4 & $-5>1$ & $+1-6>1$ & $+2-3$ & $+2-4$ & $+6-2>7$ & $+2-4$ & $+2-2$ & $+8-6$ & $+9-2$ & $+5-2$ & $+9-1$ & $+9-6$ & $+29-3$ \\
\hline & $\begin{array}{l}\text { possessive } \\
\text { pronouns }\end{array}$ & I & I & f & 1 & f & 1 & 1 & $f$ & 2 & l & 1 & 1 & 1 & 2 \\
\hline & possegsive 's & I & +7 & f & r & $+1>1$ & $+1>1$ & +3 & f & l & +5 & +2 & f & $+3>1$ & $+5>1$ \\
\hline & $\begin{array}{l}\text { possessive } \\
\text { determiners }\end{array}$ & 0 & 14 & 4 & 11 & 0 & 9 & 3 & 13 & 26 & 21 & 15 & 11 & 22 & 41 \\
\hline & V-ing & 1 & 5 & 5 & 5 & 0 & 2 & 7 & 0 & 5 & 1 & 3 & 1 & 1 & 5 \\
\hline
\end{tabular}

$+=$ supplied in obligatory context; - = not supplied in obligatory context; $>=$ oversupplied in wrong context; $/=$ no context

Table 10. Kumi’s syntactic development: Yes/No questions (re-analysis of Yamaguchi 2013)

\begin{tabular}{llcccccccccccccc}
\hline \multicolumn{1}{c}{ stage } & \multicolumn{1}{c}{ structure } & $\mathrm{t} 1$ & $\mathrm{t} 2$ & $\mathrm{t} 3$ & $\mathrm{t} 4$ & $\mathrm{t} 5$ & $\mathrm{t} 6$ & $\mathrm{t} 7$ & $\mathrm{t} 8$ & $\mathrm{t} 9$ & $\mathrm{t} 10$ & $\mathrm{t} 11$ & $\mathrm{t} 12$ & $\mathrm{t} 13$ & $\mathrm{t} 14$ \\
\hline Marked Alignment & Copula SUBJ X? & 0 & 0 & 0 & 0 & 0 & 0 & 1 & 0 & 0 & 0 & 0 & 0 & 1 & 3 \\
\hline Marked Alignment & AUX SUBJ V(O)? & 0 & 0 & 0 & 0 & 0 & 2 & 0 & 0 & 2 & 0 & 0 & 0 & 7 & 3 \\
\hline XP + Unmarked Alignmentrence & Do-canonical order? & 0 & 17 & 7 & 7 & 6 & 16 & 9 & 0 & 8 & 0 & 0 & 0 & 9 & 1 \\
\hline Unmarked Alignment & Canonical order (lexical V)? & 0 & 0 & 0 & 1 & 3 & 1 & 2 & 0 & 0 & 0 & 0 & 0 & 0 & 0 \\
\hline Unmarked Alignment & Canonical order (copula)? & 0 & 7 & 0 & 0 & 0 & 1 & 0 & 0 & 0 & 0 & 0 & 0 & 0 & 0 \\
\hline Lemma Access & Single constituent? & 1 & 5 & 0 & 1 & 0 & 5 & 3 & 1 & 2 & 0 & 0 & 0 & 6 & 0 \\
\hline
\end{tabular}

Table 11. Kumi's syntactic development: Constituent questions (re-analysis of Yamaguchi 2013)

\begin{tabular}{|c|c|c|c|c|c|c|c|c|c|c|c|c|c|c|c|}
\hline stage & structure & $\mathrm{t} 1$ & $\mathrm{t} 2$ & $\mathrm{t} 3$ & $\mathrm{t} 4$ & $\mathrm{t} 5$ & t6 & $\mathrm{t} 7$ & $\mathrm{t} 8$ & t9 & $\mathrm{t} 10$ & $\mathrm{t} 11$ & $\mathrm{t} 12$ & $\mathrm{t} 13$ & $\mathrm{t} 14$ \\
\hline $\begin{array}{l}\text { XP + Marked } \\
\text { Alignment }\end{array}$ & $\begin{array}{l}\text { Wh- AUX SUBJ } \\
\mathrm{V}(\mathrm{O}) \text { ? }\end{array}$ & 0 & 0 & 0 & 0 & 0 & 0 & 0 & 0 & 1 & 0 & 2 & 0 & 0 & 3 \\
\hline $\begin{array}{l}\text { XP + Marked } \\
\text { Alignment }\end{array}$ & $\begin{array}{l}\text { Wh- Copula } \\
\text { SUBJ X? }\end{array}$ & 0 & 0 & (1) & (1) & (3) & 0 & (3) & 1 & 3 & 0 & 1 & 8 & 6 & 4 \\
\hline $\begin{array}{l}\text { XP + Unmarked } \\
\text { Alignment }\end{array}$ & $\begin{array}{l}\text { Wh- Canonical } \\
\text { order? }\end{array}$ & 0 & 0 & 0 & 0 & 0 & 0 & 0 & 1 & 1 & 0 & 1 & 0 & 0 & 0 \\
\hline Unmarked Alignment & $\begin{array}{l}\text { In-Situ Wh- } \\
\text { Canonical order? }\end{array}$ & 0 & 0 & 0 & 0 & 0 & 0 & 0 & 0 & 0 & 0 & 0 & 0 & 0 & 0 \\
\hline Lemma Access & $\begin{array}{l}\text { Single Wh- } \\
\text { constituent? }\end{array}$ & 1 & 0 & 0 & 6 & 0 & 0 & 1 & 1 & 1 & 0 & 0 & 0 & 0 & 2 \\
\hline
\end{tabular}


Table 12. Distribution of RC constructions with single proposition and two propositions

\begin{tabular}{|c|c|c|c|c|c|c|c|c|c|c|c|c|c|c|c|}
\hline \multicolumn{16}{|l|}{ Single Proposition } \\
\hline structure/time & $\mathrm{t} 1$ & $\mathrm{t} 2$ & $\mathrm{t} 3$ & $\mathrm{t} 4$ & $\mathrm{t} 5$ & t6 & $\mathrm{t} 7$ & $\mathrm{t} 8$ & t9 & $\mathrm{t} 10$ & $\mathrm{t} 11$ & $\mathrm{t} 12$ & $\mathrm{t} 13$ & $\mathrm{t} 14$ & total \\
\hline Single proposition/Infinitival & & & 2 & 1 & & & & & & & 3 & & & 1 & 7 \\
\hline Single proposition/Participial & & & & 2 & & 7 & 5 & & 4 & & & & 8 & 2 & 28 \\
\hline Single proposition/Presentational & & & & & & & & 1 & 4 & 2 & 3 & 5 & 2 & 2 & 19 \\
\hline $\begin{array}{l}\text { Single proposition/Headless Relative } \\
\text { Clause (FOC) }\end{array}$ & & & & & & & & 3 & 1 & & 1 & & & & 5 \\
\hline $\begin{array}{l}\text { Single proposition/Relative Clause (that, } \\
\text { wh-) }\end{array}$ & & & & & & & & & 1 & & & 1 & & & 2 \\
\hline TOTAL & & & & & & & & & & & & & & & 61 \\
\hline \multicolumn{16}{|l|}{ Two Propositions } \\
\hline structure/time & $\mathrm{t} 1$ & $\mathrm{t} 2$ & $\mathrm{t} 3$ & $\mathrm{t} 4$ & $\mathrm{t} 5$ & t6 & $\mathrm{t} 7$ & $\mathrm{t} 8$ & t9 & $\mathrm{t} 10$ & $\mathrm{t} 11$ & $\mathrm{t} 12$ & $\mathrm{t} 13$ & $\mathrm{t} 14$ & total \\
\hline two propositions/Presentational & & & & & & & & & & & 1 & & & & 1 \\
\hline $\begin{array}{l}\text { two propositions/Headless Relative } \\
\text { Clause (FOC) }\end{array}$ & & & & & & & & & & & & & & & 0 \\
\hline $\begin{array}{l}\text { two propositions/Relative Clause (that, } \\
\text { wh-) }\end{array}$ & & & & & & & & & & 2 & & 1 & & & 3 \\
\hline TOTAL & & & & & & & & & & & & & & & 4 \\
\hline
\end{tabular}

Table 13 shows the results of the analysis of the grammatical functions of noun phrases (NPs) appeared in RCs. For this analysis, infinitival and participial RC constructions were not included. It is found that RC constructions started to appear in Time 8, when the child became able to produce various question forms in "Marked Alignment" and just before she attained S-procedure with morphology. The samples in (5) and (6) show RC constructions produced by Kumi in Time 8. While the grammatical function of the RC in (5) is SUBJ, the function in (6) is OBL. Kumi did not produce GEN and OCOMP in this longitudinal study.

(5) T8 one day there was a mother [who was not scared of anything]

(6) T8 this is [what you put in ... the thing]

Table 13. Grammatical function of NP in RC

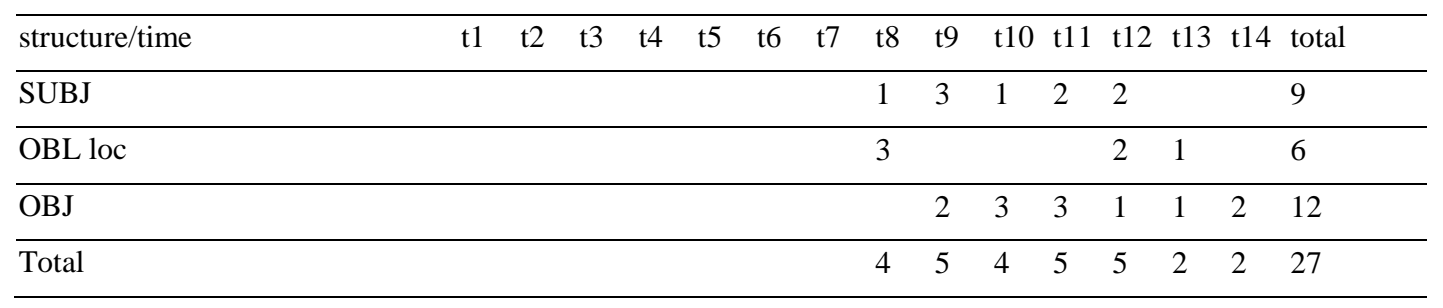

Table 14 shows the results of the analysis of grammatical functions of NPs appeared in matrix clauses. The results indicate that only one instance of center-embedded RC constructions occurred in Kumi's speech production, as in (7). This suggests that a majority of RC constructions appeared at the sentence final position, as in (8).

(7) T4 picture [hanging the wall] is the yacht picture.

(8) T13 this is a animal [that my mum and my grandma hates]

Table 14. Grammatical Functions of NP in matrix clause

\begin{tabular}{|c|c|c|c|c|c|c|c|c|c|c|c|c|c|c|c|}
\hline structure/time & t2 & t3 & t4 & t5 & t6 & $\mathbf{t 7}$ & t8 & t9 & t10 & t11 & t12 & t13 & t14 & total & $\begin{array}{l}\text { Note: } \\
\text { Position of RC }\end{array}$ \\
\hline$\overline{\mathrm{OBJ}}$ & & 2 & 2 & & 6 & 4 & & 4 & 2 & 1 & 1 & 8 & 1 & 31 & S-final \\
\hline $\begin{array}{l}\text { Complement (Copula } \\
\& \text { presentational) }\end{array}$ & & & & & 1 & 1 & 1 & 6 & 2 & 7 & 6 & 2 & 4 & 30 & S-final \\
\hline $\begin{array}{l}\text { Complement } \\
\text { (Headless, FOC) }\end{array}$ & & & & & & & 3 & & & & & & & 3 & S-final \\
\hline$\overline{\text { SUBJ }}$ & & & 1 & & & & & & & & & & & 1 & S-center \\
\hline
\end{tabular}




\section{Discussion \& Conclusions}

The present study has addressed four issues which have not been investigated extensively with longitudinal data in English L2 acquisition research as well as in PT studies. In particular, since very few longitudinal studies on the development of L2 RC constructions have been done, the findings in the current study have provided valuable evidence in SLA. Also, the processability hierarchy does not include RCs, this study should contribute to the further development of PT.

As for the relationship between the general English L2 development and the acquisition of RC constructions, the results show that infinitival and participial RC constructions emerged at early stages in the child's English L2 acquisition, and then more complex RCs emerged at Time 8, that is, around the time when the child acquired S-procedure for morphology and non-canonical alignment in question formation for syntax. This suggests that L2 learners start producing complex syntactic structures with RCs when they become able to achieve the information exchange between two different phrases, that is, noun phrases and verb phrases, and sentence formation involved with non-canonical alignment, as predicted in PT.

Concerning the acquisition order of RCs based on the NPAH, the child in this study first produced SUBJ and OBL loc and then OBJ. This finding partly supports the NPAH. However, since some types of RCs, such as GEN and OCOMP, did not appear in this longitudinal study, it was difficult to examine whether the acquisition order of RCs followed the prediction of the NPAH based on the results. While cross-sectional studies on L2 acquisition of English RCs (e.g., Doughty, 1991; Eckman, Bell \& Nelson, 1988; Gass, 1979; Izumi, 2003; Pavesi, 1986) have shown support for the NPAH, RCs hypothesized at the higher levels (i.e., GEN, OCOMP) were rarely observed in longitudinal studies on both L1 and L2 acquisition (e.g., Diessel, 2004; Mellow, 2006). Future observational studies need to develop more effective elicitation tasks to obtain data on various RCs in order to test the NPAH.

In addition, this study found that RCs with two propositions emerged after the child acquired various RC constructions expressing a single proposition. This finding is consistent with the results in child L1 acquisition research (e.g., Diessel 2004; Diessel \& Tomasello, 2000, 2001, 2005) showing that the earliest RCs produced by English-speaking children describe a single situation, while older children often use RCs expressing two situations. However, previous longitudinal studies on the use of English RCs by L2 learners (e.g., Mellow, 2006) did not address the issue of the developmental sequence of RC constructions focusing on the number of propositions. Thus, more L 2 research based on longitudinal data is needed to in order to generalize the findings in the current study.

Furthermore, since only one instance, which may be considered as center-embedded, appeared in this two-year longitudinal study, it is clear that sentence-final RC constructions are predominant. This finding is compatible with the findings in previous longitudinal research (Mellow, 2006). Thus, it can be argued that centre-embedded RC constructions acquired after sentence final-embedded RC constructions as found in L1 acquisition studies (e.g., Diessel 2004; Diessel \& Tomasello, 2000, 2001, 2005). The results in this study also support the PDH (Kuno, 1974) claiming that centre-embedded RCs are perceptually more difficult to process than sentence-final RC constructions. Moreover, it can be assumed that there is a developmental sequence within RC constructions which reflect different degree of noncanonicity since all RC constructions involve non-canonical alignment and additional non-canonicity may happen with centre-embedded RC constructions.

In conclusion, this study confirms that RC constructions are acquired when the child L2 learner reaches S-procedure stage for morphology and non-canonical alignment stage for syntax. Also, the findings demonstrate that the developmental sequence of RC constructions in child L2 acquisition is similar to that found in child L1 acquisition and generally show support for the NPAH (Keenan \& Comrie, 1977) as well as the PDH (Kuno, 1974). However, the results in this study require further elaboration of PT extension hypotheses, namely the Topic and Lexical Mapping Hypotheses (Pienemann, Di Biase \& Kawaguchi, 2005). In particular, constituent questions predicted in Unmarked Alignment Stage (i.e., In-Situ Wh- Canonical order?) did not occur in this longitudinal study. As a PT-based crosssectional study also found that Japanese university students learning English never used this type of question formation (Sakai, 2008), it is necessary to examine whether these findings can characterize a wider range of English L2 acquisition. Since this study investigated a single child acquiring English L2, more longitudinal research is clearly needed to confirm the developmental sequence of RC constructions found in this study.

\section{Acknowledgements}

We would like to thank the participants of the 13th International Symposium of Processability Theory Approaches to Language Acquisition held in Lund University, Sweden on 20-21 September 2013, for their feedback on an early version of this paper. We also wish to thank Bruno Di Biase and the anonymous reviewers for their valuable comments.

\section{References}

Baten, K. \& Håkansson, G. (2015). The development of subordinate clauses in German and Swedish as L2s: A theoretical and methodological comparison. Studies in Second Language Acquisition, 1-31. doi:10.1017/S0272263114000552 
Bloom, L. (1991). Language development from two to three. Cambridge, UK: Cambridge University Press.

Bowerman, M. (1979). The acquisition of complex sentences. In P. Fletcher \& Garman, M. (Eds.), Language acquisition: Studies in first language development (pp. 285-305). Cambridge, UK: Cambridge University Press.

Bresnan, J. (2001). Lexical-functional syntax. Oxford: Blackwell.

Bresnan, J., \& Mchombo, S. (1987). Topic, pronoun, and agreement in Chicheŵa. Language, 63(4), 741-782.

Dalrymple, M. (2001). Syntax and semantics: Lexical Functional Grammar. San Diego, CA: Academic Press.

Di Biase, B. \& Kawaguchi, S. (2002). Exploring the typological plausibility of Processability Theory: Language development in Italian second language and Japanese second language. Second Language Research 18 (3), 272-300.

Di Biase, B., Kawaguchi, S., Yamaguchi, Y. (2015). The development of English as a second language. In C. Bettoni, \& B. Di Biase (Eds.) Grammatical development in second languages: Exploring the boundaries of Processability Theory. European Second Language Association.

Diessel, H. (2004). The acquisition of complex sentences. Cambridge, UK: Cambridge University Press.

Diessel, H. \& Tomasello, M. (2000). The development of relative clauses in spontaneous child speech. Cognitive Linguistics, 11 (1-2), 131-151.

Diessel, H. \& Tomasello, M. (2001). The acquisition of finite complement clauses in English: a corpus-based analysis. Cognitive Linguistics, 12(2), 97-141.

Diessel, H. \& Tomasello, M. (2005). A new look at the acquisition of relative clauses. Languages, 81 (4), 882-906.

Doughty, C.J. (1991). Second language instruction does make a difference: Evidence from an empirical study of SL relativization. Studies in Second Language Acquisition, 13, 431-469.

Eckman, F. R. (1977). Markedness and the contrastive analysis hypothesis. Language Learning, 27, 315-330.

Eckman, F. R. (1984). Universals, typologies and interlanguage. In W. E. Ruthherford (Ed.), Language universals and second language acquisition (pp. 79-105). Amsterdam: John Benjamins.

Eckman, F.R., Bell, L., \& Nelson, D. (1988). On the generalization of relative clauses instruction on the acquisition of English as a second language. Applied Linguistics, 9, 1-20.

Eckman, F. R. (1996). A functional-typological approach to second language acquisition theory. In W. C. Ritchie \& T. K. Bhatia (Eds.), Handbook of second language acquisition (pp. 33-68). San Diego, CA: Academic Press.

Fitz, H., Chang, F., \& Christiansen, M. H. (2011). A connectionist account of the acquisition and processing of relative clauses. In E. Kidd (Ed.), The acquisition of relative clauses: Processing, typology and function (pp. 39-60). Amsterdam; Philadelphia: John Benjamins.

Gass, S. (1979). Language transfer and universal grammatical relations. Language Learning, 29, 327-344.

Hawkins, J. A. (1987). Implicational universals as predictions of language acquisition. Linguistics, 25, 453-473.

Itani-Adams, Y. (2007). One child, two languages: Bilingual first language acquisition in Japanese and English. $\mathrm{PhD}$ thesis, University of Western Sydney, Sydney.

Izumi, S. (2003). Processing difficulty in comprehension and production of relative clauses by learners of English as a second language. Language Learning, 53, 285-323.

Keenan, E., \& Comrie, B. (1977). Noun phrase accessibility and universal grammar. Linguistic Inquiry, 8, 63-99.

Kidd, E. \& Bavin, E. L. (2002). English-speaking children's comprehension of relative clauses: Evidence for generalcognitive and language-specific constraints on development. Journal of Psycholinguistic Research, 31, 599-617.

Kroeger, .P.R. (2005). Analyzing grammar: An introduction. Cambridge, UK: Cambridge University Press.

Kuno, S. (1974). The position of relative clauses and conjunctions. Linguistic Inquiry, 5, 117-136.

Lambrecht, K. (1988). There was a farmer had a dog: syntactic amalgams revisited. Berkeley Linguistics Society, 14, 319-339.

Limber, J. (1973). The genesis of complex sentences. In T. E. Moore (Ed.), Cognitive development and the acquisition of language (pp. 169-185). New York: Academic Press.

MacWhinney, B., \& Pleh, C. (1988). The processing of restrictive relative clauses in Hungarian. Cognition, 29, 95-141.

Mellow, D. (2006). The emergence of second language syntax: A case study of the acquisition of relative clauses. Applied Linguistics, 27, 620-644.

Pavesi, M. (1986). Markedness, discoursal models, and relative clause formation in a formal and informal context. Studies in Second Language Acquisition, 8, 38-55.

Pienemann, M. (1998). Language processing and second language development: Processability Theory. Amsterdam: John Benjamins.

Pienemann, M. (Ed.) (2005). Cross-linguistic aspects of Processability Theory. Amsterdam: John Benjamins. 
Pienemann, M., Di Biase, B., \& Kawaguchi, S. (2005). Extending Processability Theory. In M. Pienemann (Ed.) Crosslinguistic aspects of Processability Theory (pp. 199-251). Amsterdam: John Benjamins

Pienemann, M. \& Keßler J-U. (2011). Studying Processability Theory. Amsterdam: John Benjamins.

Sakai, H. (2008). An analysis of Japanese university students' oral performance in English using processability theory. System, 36(4), 534-549.

Schumann, J.H. (1980). The acquisition of English relative clauses by second language learners. In R. Scarcella, C. \& Krashen, S. (Eds.), Research in second language acquisition: Selected papers of the Lost Angeles Second Language Acquisition Research Forum (pp. 118-131). Rowley, MA: Newbury House

Sheldon, A. (1974). On the role of parallel function in the acquisition of relative clauses in English. Journal of Verbal Learning and Verbal Behavior, 13, 272-281.

Yamaguchi, Y. (2013a). Child second language learning: A study of English as a second language acquisition. Saarbrücken, Germany: LAP Lambert Academic Publishing.

Yamaguchi, Y. (2013b). The acquisition of complex structures: The case of child ESL. Open Journal of Modern Linguistics, 3(3), 2013.

Yamaguchi, Y. \& Kawaguchi, S. (2013). Developing relative clause constructions in English as a second language. Paper presented in the $13^{\text {th }}$ International Symposium of Processability Approaches to Language Acquisition (PALA 2013), Lund University, Sweden, 20-21 September, 2013.

Yamaguchi, Y. \& Kawaguchi, S. (2014). Acquisition of English morphology by a Japanese school-aged child: A longitudinal study, The Asian EFL Journal Quarterly, 16(1), 89-119. 